Marcilio Marques Moreira, exdiplomata, professor universitário, freqüente conferencista no Brasil e no exterior, autor de livros e artigos e também administrador de grupo financeiro privado nacional.

\title{
O Brasil no mercado financeiro internacional
}

\section{Premissas}

Antes de examinar a própria temática da dívida externa, cabe iniciar com algumas premissas.

A primeira, que o Brasil é, e continuará sendo, importador líquido de poupanças externas - e o foi desde a Independêcia. Da mesma maneira que nós tivemos, como dizia João Camillo de Oliveira Torres, governo antes de ter povo, nós assumimos dívida antes de ter conquistado a independência política e econômica.

A internação de poupanças externas tem assumido formas diferentes, às vezes ingressando no país como investimentos diretos, às vezes em forma de financiamentos. Essa variação tem ocorrido tanto em função de opções nossas, como em função de flutuações do próprio mercado internacional. Âs vezes, preferimos o endividamento, outras vezes, privilegiamos o investimento direto; às vezes, o mercado internacional prefere financiar-nos, outras, investir aqui. É da confluência desses interesses que ,num momento ou em outro, sobressaem afluxo de investimentos ou acumulação de endividamento.

É mesmo possivel traçar uma periodização desses movimentos pendulares, distinguindo o comportamento das diversas décadas recentes. Os capitais internacionais no pós-guerra, sobretudo os privados, preferiram, até começo de 70 , quando ocorreu o choque do petróleo, vir em forma de investimentos diretos. A grosso modo, a década dos 50 correspondeu a um esforço desses investidores externos para pular barreiras alfandegárias; na década dos 60,0 interesse principal parece ter sido o de procurar mão-de-obra mais barata, além de participação em mercado de grande potencial; na década dos 70, as empresas já tinham estratégia mais diversificada, correspondente à transnacionalização da economia mundial que estava ocorrendo. Em meados dessa década, após o choque do petróleo, houve marcada intensificação dos fluxos financeiros em forma de endividamento. 
1. Desenvolvi o tema em conferência no Banco Central, em outubro de 1978, publicada na coletânea de ensaios meus reunidos em De Maquiavel a San Tiago. Brasilia, Universidade de Brasília, 1981. p. 11330.
Do lado brasileiro, nos anos 50, sobretudo no período Juscelino Kubitschek, preferimos os investimentos diretos, mesmo aqueles na forma da Resolução no 113, que regulava o internamento de equipamentos, inclusive usados. Assim, foi instalada no país a indústria automobilística, bem como a de muitos bens duráveis de consumo. $\mathrm{Na}$ década de 60, à época em que foi promulgada a lei n: 4.131 (1962), a chamada lei de remessas de lucros, a preferência brasileira pelo endividamento era nítida. Argumentava-se ser preferivel pagar juros a acolher no país investidores externos, que procurariam participar das decisões internas e disputar parcela do poder econômico.

Aquela preferência sobreviveu às mudanças de 64 e até se acentuou em alguns casos; exemplo foi o acordo que havia sido rubricado, em maio de 1963, sobre a compra das empresas concessionárias de serviços de eletricidade de propriedade americana, do grupo AMFORP. Havia sido negociada cláusula pela qual os vendedores se obrigavam a reinvestir no país parcela do montante global. Em 1964, o acordo foi rerratificado, com uma mudança importante, a de que aquele reinvestimento direto fosse transformado em dívida, alongando-a de 25 para 45 anos. A opção financeira não foi, em geral, abrangente e procurou-se atingir posição balanceada entre financiamentos e investimentos diretos. Para estimular estes, promoveu-se, pouco depois, a uma revisão, pela lei nº 4.390 da de n. 4.131 -flexibilizando-a sem transfigurá-la - e celebraram-se o Acordo de Garantias de Investimentos com os Estados Unidos e tratados de bitributação com muitos países exportadores de capital.

Fase nova iniciou-se em 73-74, à época em que o euromercado que começava a expandir-se, recebeu enorme injeção de petrodólares. Para assegurar a aplicação rentável e sem delongas desses recursos, o mercado internacional passou a privilegiar o fluxo financeiro, em vez do de investimentos diretos. Tanto assim, que a entrada de in vestimentos diretos para o Brasil, desde então até agora, tem correspondido a apenas algo entre 10 a $20 \%$ do ingresso das poupanças externas. Esta relação, em empresa privada, seria considerada desequilibrada, se comparado capital de risco com capital de empréstimo.

O fluxo financeiro, em contraste, foi muito expressivo. Tomando apenas o período de 74 a 79, quer dizer, cinco anos, ingressaram no país 35 bilhões de dólares, líquidos. Embora levando em conta que estamos falando de moedas em tempos diferentes, é interessante lembrar que todo o Plano Marshall envolveu 25 bilhões de dólares e a Aliança para o Progresso, se tivesse sido realizada como concebida, abarcaria transferência em 10 anos, sob todas as formas públicas e privadas, de investimentos diretos ou financeiros, de apenas 20 biIhões de dólares; mesmo deflacionando-se o dólar, a comparação é impressionante. Mecanismo de mercado, no caso o mercado das euromoedas, produziu, de fato, um dos mais importantes fluxos de transferência financeira ocorridos no periodo de pós-guerra, comparável ao volume do Plano Marshall1. Tratava-se, de fato, da contramão financeira do enorme deslocamento real, e monetário, ocorrido em favor dos paises exportadores de petróleo, que impuseram ao mercado uma espécie de imposto sobre o consumo de combustíveis. Como os sistemas internacionais de pagamento tendem a um equili- 
2. É a estimativa de A. C. Pastore, baseada em estudos de Langoni e Bacha. Cf. Comentários. In: Estudos sobre o desenvolvimento econômico. Rio de Janeiro, BNDE, 1977. p. 42. No mesmo sentido, o argumento de Millord Long e Franck Veroso. The debtrelated problems of non-oil less developed countries. In: ECOnomic development and cultural change, 2. (3): p. 514-5, Apr. 1981.

3. Isto significa um encurtamento, de fato, do prazo dos empréstimos, pois a diferença entre o juro nominal e o juro real corresponde a uma antecipação, não prevista, da tabela de amortizações brio, a esse deslocamento em direção dos países da OPEP correspondeu movimento inverso, quer através de importações acrescidas, quer através de transferência compensatória de haveres financeiros, para custear os déficits dos balanços de pagamento. Era a reciclagem dos petrodólares.

\section{Oendividamento externo}

O Brasil, por sua vez, apercebendo-se de que havia emprestadores potenciais, candidatou-se a tomador desses recursos, a fim de financiar o pagamento daquele imposto e, dessa maneira, ganhar tempo para promover os ajustamentos necessários. Foi política bastante consciente: naquela época os juros nominais eram muito mais baixos do que hoje e, sobretudo, os juros reais, ao menos até 1980 , oscilaram de 0 a $3 \%$. Se se considerar que a taxa média de retorno interno dos investimentos no Brasil gira em torno de $15 \%$ reais 2 , vê-se que havia nítida margem positiva, isto é, ganho liquido em termos de valor presente. Portanto, o endividamento foi opção inteligente, às taxas de juros reais prevalecentes, passando os fatores críticos a serem a boa destinação dos recursos recebidos, canalizando-os não para financiar o consumo, mas, sim, investimentos prioritários, e a oportunidade e extensão dos ajustamentos (a alternativa do endividamente pode anestesiar a vontade de introduzir as correções adequadas) às novas realidade econômicas: escolha, acertada em termos de aplicação em projetos de rentabilidade interna comprovada, em termos de estratégia macroeconômica, assim como em termos de geração de produtos que se possam exportar para pagar o serviço daquele endividamento, ou que se deixem de importar.

Evidentemente, a irrupção do segundo choque do petróleo e a brusca elevação das taxas de juros internacionais mudaram a situação; hoje em dia, nos Estados Unidos, as taxas reais de juros giram em torno de $7 \%$, nível inédito comparado com a taxa histórica para aquele país, que tem sido calculada em cerca de 2 a $3 \%$. De modo que a dívida, ao novo custo, passou a ser alternativa bem menos atraente, exigindo, daqui por diante, seletividade ainda mais rigorosa. Esperase, éverdade, que os juros reais decresçam, mas a maioria dos analistas prevê que não descem abaixo de $3 \%$ reais. A década de 80 , portanto, significaria não só o início de um ciclo econômico da energia cara, mas também do dinheiro caro. Acresce lembrar que juros nominais altos criam, sobretudo, problemas de fluxo de caixa3, enquanto que juros reais elevados atingem a própria rationale de contar-se, ou não, com uma alavancagem de recursos de terceiros.

\section{Oendividamento e a "Nova Ordem Econômica Internacional"}

Quanto ao dilema "negociação versus confronto", proposto por alguns estudiosos do tema, aqui e em outros países devedores, notadamente no México (cuja dívida externa está perto de atingir a brasileira em dimensão absoluta e que, portanto, em termos relativos, a ultrapassa), reflete dicotomia espúria, pois, se a negociação parece constituir o único caminho que evita a ruptura, sempre estéril em re- 
sultados duradouros, a negociação necessariamente se impõe, para atender aos interesses dos devedores, a partir de uma posição legítima de força, o que, em termos de tática, pode incluir posições de firmeza, uma vez respeitadas as regras do jogo do forum em que for realizada. Assim, do momento em que o país resolveu recorrer ao mercado internacional privado de capitais para custear suas necessidades financeiras externas e que combate o protecionismo comercial por atentar contra o princípio de livre competição, não pode, simultaneamente, acolher ideologia que sustenta que o mercado em si é algo intrinsecamente perverso e injusto. O mercado, como mecanismo regulador das relações econômicas, tanto no âmbito interno, quanto internacional, é sistema eticamente neutro, que pode e deve, por meio de compensações que transitam através de um processo politi$\mathrm{co}$, ser dirigido para produzir os efeitos sociais desejados pela comunidade respectiva.

A partir dessa premissa, cabe empreender todos os esforços para a implantação de uma Nova Ordem Econômica Internacional, o tema da Conferência de Chefes de Estado ou Governo, de Cancun, em outubro último, mas não se concebe essa "nova ordem" como sistema de planificação estatal a nivel mundial, que iniba o funcionamento dos legítimos mecanismos de mercado.

Os problemas de endividamento dos países em desenvolvimento, sobretudo daqueles não-exportadores de petróleo, decorrem, é óbvio, tanto de problemas internos, quanto de problemas estruturais e conjunturais da própria economia mundial. A administração contínua do endividamento externo, mesmo que realizada em forma difusa, correspondente à pulverização do sistema financeiro internacional, não exclui, mas deve ser conduzida coerentemente com as posições assumidas em favor da implantação de uma Nova Ordem Econômica Internacional. É claro que não podemos esperar que esta se implante, para, só então, procurar equacionar de maneira mais duradoura e tranqüila a problemática de nosso endividamento. E não se pode esperar, no sentido de uma espera cronológica, porque não há tempo para isso, nem se deve esperar, no sentido metafórico do termo, que a Nova Ordem Econômica Internacional vá criar para os países em desenvolvimento uma espécie de maná financeiro internacional. Temos que lutar por melhorias, mas devemos conscientizar-nos de que esses avanços serão muito mais aluvionais, gradativos, do que revolucionários ou milagrosos. Temos, pois, que procurar manter coerência entre nossa posição no diálogo Norte-Sul, de solidariedade com o terceiro mundo, e a posição de país de industrialização recente (ou tardia, como querem alguns) - um newly industrialized country (NIC) com que nos apresentamos perante a comunidade financeira internacional e os mercados para nossos produtos industriais. Caso contrário, deslegitimaremos uma e outra posição.

$\dot{E}$, nessa perspectiva, que tem de ser encarada a mundialização de economia. É fenômeno que não pode ser "jogado debaixo do tapete", nem ser exorcizado com discursos radicais. O fenômeno existe e está aí para ficar e, portanto, tem que ser gerenciado pelos Estados nacionais no interesse dos respectivos povos: o Estado nacional ainda é poder incontrastado, que pode e deve defender, com força sufi- 
4. O fenômeno é analisado, com inteligência e profusão de dados, na obra patrocinada pelo Atlantic Institute for International Affairs, de Benjamin J. Cohen lem colaboração com Fábio Basagni), Banks and the balance of payments: private lending in the international adjustment process. Montclair, Allanheld, Osmun, 1981. ciente, a preservação dos objetivos nacionais permanentes, perante as empresas multinacionais.

\section{Privatização da criação da liquidez internacional}

Por sua vez, o mercado financeiro internacional tem, hoje, uma dimensão, complexidade, multipolarização, e difusão que o distinguem do mercado de 20 anos atrás, do ano 61, por exemplo, quando Jânio Quadros conduziu o processo de consolidação da dívida brasileira, envolvendo mais de 2 bilhões de dólares, naquela época uma das maiores operações financeiras individuais já realizadas até então por qualquer país dó mundo.

Na década dos 50 até o início da dos 70, o mercado financeiro ainda era regulado, em grande medida, pelo Fundo Monetário Internacional, que lhe servia de banco central. E atrás do FMI havia duas forças a sancioná-lo: o dólar, ainda lastreado no, e referido ao, ouro, e - Tesouro Americano, que usava do seu direito de senhoriagem para cunhar moeda e com ela atender a suas necessidades financeiras. Ele imprimia dinheiro, que era aceito como uma taxa que o mundo estava disposto a pagar, a fim de ter uma moeda internacional estável e acatada universalmente como reserva internacional. O choque do dólar, - Nixon shock de 1971, que desvinculou a dólar do ouro, e iniciou a sua sucessiva desvalorização, acompanhando a escalada da inflação e a acumulação dos déficits em conta corrente dos Estados Unidos processo só invertido nos últimos meses - coincidiu com a erosão relativa do poderio político e militar americano e privou os Estados Unidos da autoridade que sancionava, em última instância, a estabilidade do sistema monetário internacional. Sem a autoridade capaz de bancar a credibilidade do sistema implantado desde Bretton Woods (1944-45), com taxas de câmbio passando a flutuar de modo errático e, ainda, com a privatização, pelo surgimento do euromercardo, da criação da liquidez internacional, pulverizaram-se, em conseqüência, os atores do sistema financeiro internacional, que deixou de estar sujeito a uma política geral4. O diálogo com o novo sistema, de múltiplos atores e de grande flexibilidade, passou, assim, a ser, de nossa parte, muito mais plural, capilar, muito mais complexo do que naquela época.

Essa nova realidade, pulverizada, explica a dificuldade de o país apresentar-se, por sua vez, como um único ator perante essa comunidade multipolarizada, como no caso do empréstimo-jumbo negociado em fins de 1979, no valor de 1 bilhão e 200 milhões de dólares. Nesse caso, os bancos-líderes, que assumiram a sua parcela, na intenção de repassar boa parte, tiveram dificuldade em fazê-lo e foram obrigados a reter a maior parte de seus compromissos, ficando um travo amargo na comunidade financeira. Esta prefere diversificar os seus riscos, mesmo sabendo que, em última instância, qualquer empréstimo ao Brasil acabará por ser uma forma de financiar o déficit das contas externas brasileiras. Aquele mal-entendido contribuiu para alienar a boa vontade da comunidade financeira, já pouco propensa a concordar com as políticas adotadas em $79 / 80$, de combate à inflação e ao desequilíbrio cambial, e de captação de recursos externos, 
5. São, respectivamente, o Banco Central, o Controlador da Moeda lórgão de fiscalização do sistema de bancos nacionais) e a Empresa de Seguros dos Depósitos Bancários, entidades autônomas entresí.

6. Bank of International Settlements, sediado na Basiléia, que funciona como caixa central de liquidação ou clearing house (câmara de compensaçãol, para os países desenvolvidos ocidentais. Os prós e contras de regular o euromercado foi tema de interessante relatório do THE ATLANTIC COUNCIL'S WORKING GROUP ON INTERNATIONAL MONETARY AFFAIRS, In: The International Monetary System in Transition. Washington, D.C., May 1980. esp. p. 34-9. que considerava pouco realistas na concepção e muito rígidas em termos de spreads (taxa de risco), justamente no momento em que atravessávamos grandes dificuldades.

É claro que essa pulverização e privatização da criação da liquidez internaciona/ trouxe consigo, como conseqüência positiva não programada, a despolitização dos acessos ao crédito internacional, antigo pleito do Brasil nos foros internacionais.

Como os riscos de crédito, mesmo os soberanos, são hoje assumidos preponderantemente por uma variedade de agentes privados, em múltiplos países, ele estão sujeitos às mais diversas regras e avaliações. Nos bancos americanos os empréstimos estão sujeitos à supervisão de três órgãos federais (sem falar nos órgãos estaduais), que podem mudar a classificação dos créditos a ponto de torná-los interessantes ou desinteressantes para o banco. No caso de agências federais, o Federal Reserve Board, o Comptroller of the Currency ou a Deposit Insurance Corporation 5 têm poder suficiente para considerar o país mutuário como normal; como sujeiro a report, o que implica na obrigação de informar a autoridade sobre qualquer empréstimo ao país, sem que haja objeção a priori; como devedor arriscado; como país cujo débito tem de entrar diretamente no rol dos de liquidação duvidosa. Em outros países financiadores, as regras já são outras, de modo que, havendo tantos países (e mesmo órgãos reguladores estaduais, como nos Estados Unidos) e tantos agentes, pode-se perceber como é complexo e delicado qualquer tipo de negociação que se queira fazer de caráter globai. Acresce que ainda persiste, como uma espécie de espada de Dâmocles a pender sobre o mercado financeiro internacional, a tentativa de vários bancos centrais, sobretudo através do BIS6, para regulamentar, ou, ao menos, supervisionar o mercado de euromoedas. Há pois, uma complexidade e uma delicadeza - os mercados financeiros são muito nervosos - de modo que qualquer abordagem teria de ser feita com extrema cautela e segurança.

\section{Renegociação da dívida}

Quanto ao tema que tem sido levantado em debates da mais variada ordem sobre a necessidade, conveniência ou possibilidade de renegociação da dívida externa, parece necessário colocar duas posições principais.

A dívida já assumida é perfeitamente administrável. O principal da dívida não deve preocupar em demasia. É da natureza das relações internacionais e das relações econômicas internas que, no endividamento correspondente ao capital de giro permanente, isto é, aquele que não é transitório, apenas para atender a uma situação emergencial, nem tomador nem emprestador esperam que a dívida vá ser liquidada; já se antecipa que ela vá ser renovada, que ocorra um roll-over embora se espere que os prazos sejam formalmente respeitados.

Já os juros preocupam mais, porque ai ocorre realmente uma transferência efetiva, sobretudo quando praticados em níveis reais tão altos como os prevalecentes no momento. Como já observado, a situação de agora é, nesse sentido, diferente, e mais preocupante do 
7. A SURVEY by the staff of the International Monetary Fund. Occasional paper $n$ : 4 . Washington, D.C., IMF, World Economic Outlook. p. 78, jun. 1981 que a de até 1980, Mesmo assim, a dívida pretérita é gerenciáve/ na dimensão que tem hoje. Não é desmesurada em relação à dimensão do mercado financeiro internacional como um todo, nem é desproporcional em relação ao produto do Brasil ou às exportações. O próprio FMI, ainda recentemente, mostrou que, levando-se em conta o crescimento das exportações e o aumento do produto mundial, as dívidas dos países em desenvolvimento, sobretudo os de industrialização recente, deixaram de crescer desde 19787

\section{Oportunidade do crédito futuro versus problema da dívida pretérita}

Talvez fosse mais útil, e mais positivo, portanto, deixar de pensar-se na renegociação da dívida pretérita (que já é feita implicitamente ao ser "rolada"), para pensar-se na negociação do crédito futuro do país. quer dizer, não olhar a dívida em termos de problema, mas olhar o crédito do país em termos de oportunidade. Em vez de ruminar o passado, mais vale pensar na construção do futuro.

Há que considerar-se, também, a interpenetração entre a política de endividamento, que é uma política setorial enfocada para o balanço de pagamentos, e as outras políticas setoriais de âmbito interno. Para que estas não tenham de subordinar-se, em demasia, à primeira, pode interessar ao país, em um certo momento, procurar negociar um entendimento, que talvez nem precise traduzir-se em instrumentos formais, com o qual se assegurasse uma espécie de tranqüilidade, digamos, de três anos, em termos de acesso ao crédito internacional. A partir desta, se não segurança absoluta, ao menos margem adicional de manobra conquistada pela convicção de que não teríamos obstáculos para o acesso aos créditos futurọs de que precisarmos durante o período (seria uma espécie de crédito stand-by informal), poder-se-ia passar a administrar a economia interna com mais autonomia, pois menos angustiados pela espectro da asfixia cambial.

É nesse contexto que me parece que, embora do ponto de vista das necessidades e possibilidades imediatas, o recurso, agora, ao Fundo Monetário Internacional não pareça oferecer vantagens, podendo, ao contrário, despertar desconfiança ou introduzir inflexibilidades inconvenientes, a hipótese não deve ser afastada para eventual utilização futura, o que poderá ser dificultado, no caso de insistirmos em analisá-la em termos simplistas e demonológicos. Como disse San Tiago, em lúcido discurso perante a televisão, em 14/5/63, "não faz o Fundo boa figura de moinho de vento para que partamos contra ele de lança em riste, sem primeiro identificar a sua verdadeira natureza e compreender o alcance do que com ele pretendemos acertar".

É claro que o Fundo, como já anteriormente referido à exaustão, não mais exerce o papel que preencheu no passado, nem dispõe de recursos financeiros, mesmo caso desejasse, para representar solução ao problema de nosso endividamente. Muito menos poderia fornecer meios para uma renegociação global de nossa dívida, pois sua função até hoje tem sido muito mais no sentido de atender a situações 
8. Haviam sido propostos três caminhos para alargar os recursos do FMI: novo aumento das quotas dos PaísesMembros; autorização para emitir novos lotes de DES (direitos especiais de saque) e captação de recursos nos mercados privados de capital. Os Estados Unidos opuseram-se às três alternativas e também votaram contra o empréstimo à Índia, concedido com prazo de 10 anos (superior, portanto, aos prazos normais do FMI) ea juros fixos de 9 e $10 \%$. Limitação adicional da atuação do FMI prende-se à necessidade de reservar recursos para eventual atendimento à China, admitida ano passado, é à Hungria e Polônia, que estão postulando seu ingresso na organização. transitórias do que eștruturais. O próprio Brasil, na 1a UNCTAD, propôs que os débitos com o FMI fossem transferidos ao Banco Mundial, sempre que os problemas aparentemente conjunturais provassem ser estruturais.

Não obstante, o Fundo ainda poderia ser útil, sem, provavelmente, exigir grau de austeridade superior à já hoje praticada, nos seguintes casos:

a) como válvula de segurança para atender emergência cambial provocada por fatores contingentes imprevistos, como o de estreitamento súbito da liquidez internacional induzido por conflagração inesperada;

b) como avalista técnico e acompanhador de programa de médio prazo, o que seria importante sobretudo para instituições financeiras de menor porte que não disponham de suficiente corpo técnico;

c) como fornecedor de crédito stand-by por três anos: mesmo que não seja necessário utilizá-lo, daria certa tranqüilidade, em termos de aporte líquido marginal de novos recursos;

d) como hospedeiro catalisador, útil para dar um mínimo de unidade ao diálogo com credores pulverizados.

Evidentemente, isto não é algo que se poderia, de um dia para outro, concretizar. Por outro lado, a atitude do novo governo norteamericano, de dificultar o acesso do Fundo a novas fontes de recursos e de tornar menos flexíveis as condicionalidades exigidas, torna a hipótese mais difícil, sobretudo depois que foi concedido à İndia, em novembro de 1981, empréstimo stand-by de 5,8 bilhões de dólares, a serem sacados nos próximos três anos8.

Qualquer entendimento mais abrangente com o FMI e/ou outras instituições financeiras do exterior não poderia surgir de um programa especialmente elaborado para tal fim, mas deveria basear-se em estratégia interna de médio prazo, digamos, de 3 a 5 anos, que, além da coerência técnica, conte com respaldo político e aceitação pública, que lhe confiram legitimidade, isto é, autoridade, eficácia e poder de mobilização. Em reação ao excesso de ambição quanto a objetivos e possibilidades de previsão quantitativa, que minaram a plausibilidade do $2^{\circ}$. Plano Nacional de Desenvolvimento EconômicoSocial, o $3^{\circ}$ Plano não inclui nenhuma previsão quantitativa, não aspira a ser uma estratégia a médio prazo, nem constitui-se em documento político, como o foi o Plano de Metas no Governo Kubitschek.

O saneamento e a reordenação, a mais longo prazo, da economia, uma vez superada a atual fase conjuntural recessiva, exigirão, entretanto, um mínimo de programação mais sistemática, que permita ao país, e também aos seus credores, um horizonte temporal, equivalente, a grosso modo, ao prazo médio dos empréstimos que lhes solicitamos, sem precisar traçar um quadro minucioso e inflexível. A comunidade financeira internacional sabe, tão bem quanto nós, que temos capacidade para administrar a divida, mas gostaria de vislumbrar um horizonte econômico a médio prazo, com indicação de problemas e oportunidades e o esboço de uma política, de como enfrentá-los. 
9. Sobre o assunto, são pertinentes os comentários alinha. dos por Alberto O. Hirschman em estudo sob o título "The changing tolerance for income in the course of economic development", incluído no seu último livro Essays in trespassing: economics to politics and beyond. Cambridge University Press. p. 39-58.
É freqüente a indagação quanto às chances de estabilidade da política econômica, face às oscilações no passado recente. Em especial, perguntam os credores - em paralelo, aliás, à perplexidade da própria sociedade brasileira - quando e como pensamos superar o atual ciclo recessivo de nossa economia, que equivale à nossa primeira crise industrial moderna. O relançamento, quando vier, não irá reacender a inflação ou a propensão a importar, colocando em perigo os progressos já alcançados? O que estamos realizando e, sobretudo, o que pretendemos realizar, em termos de ajustamentos mais duradouros, mais estruturais, para não dependermos tanto das poupanças externas, quanto nos últimos anos? Quais são as diretrizes gerais, em termos de uma política de ingressos, i.e., de uma política mais harmônica de remuneração dos fatores de produção? Qual é a proposta brasileira para enfrentar, de maneira realista e efetiva, o desafio da má distribuição de renda e de riqueza, problema estrutural de longo prazo, mas cujo iníci৫ de equacionamento não permite mais adiamentö? Além de desejar perscrutar com maior clareza - embora consciente que a incerteza inere aos processos econômicos - tendências da evolução a médio prazo, a comunidade econômica mundial procura cada vez mais analisar fatores não-econômicos, que tem visto influenciar, em última instância, o comportamento de tantos países que fizeram as manchetes nos últimos anos: o problema social, o problema das desigualdades pessoais e regionais 9 , os desafios da educação, saúde, nutrição, habitação, vestuário, transporte de massa, en fim, as necessidades básicas da população. Já tive, anteriormente, oportunidade de assinalar que o Brasil perde em legitimidade, portanto, em eficácia, ao apresentar-se nos foros internacionais em favor de um diálogo Norte-Sul, de uma Nova Ordem Econômica Internacional, baseada em princípios de justiça comutativa e justiça distributiva, sem que diálogo interno paralelo seja praticado em escala suficiente, quando não temos uma política nacional de estreitamento das diferenças de renda. A que separa São Paulo do Nordeste, por exemplo, é maior do que a diferença entre o Brasil, como um todo, e os Estados Unidos.

Enquanto nossa imagem se beneficia com os avanços do processo de abertura, que despertou a simpatia da comunidade internacional, que acompanha, com interesse, o projeto de reinstitucionalização política e de alargamento de sua base consensual, qualquer incoerência entre o nosso discurso internacional e a nossa realidade interna face à questão social pode prejudicar-nos, diretamente, nos organismos mundiais e, indiretamente, no mercado financeiro internacional.

Os maiores bancos e os grandes grupos econômicos dispõem hoje, nas suas equipes de análise, de cientistas políticos que procuram tracejar não o caminho que o país estudado vá seguir, necessariamente (porque esses caminhos são, e sempre serão, desconhecidos), mas cenários alternativos. Depois de Cuba, depois do Irã, da Polônia, da instabilidade no Oriente Médio ou da América Central, e de outros sustos inesperados, as considerações políticas começam a exercer papel crescente, em função dos padrões de distribuição de renda, acumulação de tensões sociais e econômicas, ou de outras deman- 
10. A SURVEY by the staff of the International Monetary Fund. Occasional paper n: 4. Washington, D. C., IMF. World Economic Outlook. p. 6. jun. 1981

11. Uma boa análise da gênese do conceito no Banco Internacional e de seus desdobramentos encontra-se em: CLARK, William. Robert McNamara at the World Bank. In: Foreign Affairs. Fall, 60 (1) p. 167-84, 1981. Veja também World Development Report: 1980 (publicado para o Banco Mundial pela Oxford University Press), especialmente a Parte II: "Poverty and human development, p. 32-94. Também, HUMAN development; a continuing imperative, Washington, D.C., The World Bank. World Development Report: 1981. p. 97-110, aug. 1981. das da sociedade, de natureza política, como as que pleiteiam maior voz e participação nos processos decisórios. Como os bancos nos estão concedendo empréstimos de prazo de 8 ou mais anos, dentro da Resolução n. 63 ou da Lei n. 4.131, e as empresas industriais estão investindo com horizontes ainda mais longos, as considerações de largo prazo passam a assumir importância, no mínimo equivalente às de curto prazo, com as da liquidez imediata.

Colocação perante a comunidade econômica internacional, mais abrangente no tempo e no escopo da reflexão envolvida, pressupõe, se não um novo pacto social - difícil de definir ou impossível de atingir - mas, diretrizes a médio prazo e indicações mais dilatadas de como o país, de como a sociedade, de como o governo pensam gerenciar a crise econômica e retomar o desenvolvimento, sem exacerbar a inflação ou agravar as contas externas, como pensam superar as diferenças sociais e regionais, como pretendem conduzir o processo de reinstitucionalização política.

Plataforma dessa natureza, ou agenda comum de prioridades nacionais, teria de transitar, necessariamente, por um processo interno que the conferisse densidade política, para poder servir de lastro a uma negociação do crédito futuro, e não da dívida passada.

E qualquer negociação teria de iniciar-se por mais constante e mais aprofundada parlamentação, não só com poucos interlocutores privilegiados como na década de 60 , se não com múltiplos agentes econômicos. E apesar de todas as idiossincrasias que suscita, um dos interlocutores potenciais deveria ser o FMI. Não obstante a crosta de rigidez e conservadorismo, de que ainda não conseguiu livrar-se, o FMI tem interesse em negociação do tipo, como o provou o financiamento à İndia, para livrar-se da imagem de que apenas interfere in extremis, quando a economia dos pacientes já está à beira do colapso. Sua ajuda identificou-se, assim, na opinião pública, como o beijo da morte. O último World Economic Outlook 10 mostra que, hoje em dia, o FMI não privilegia mais exclusivamente as políticas monetárias e fiscal em detrimento de outros tipos de política, como, por exemplo, as que procuram agir sobre a oferta (supply-side economics), as que se preocupam com a reestruturação e os reajustes a mais longo prazo da economia, e mesmo as políticas de ingressos mais harmônicos (incomes policy). O Banco Internacional poderia, também, exercer papel mais positivo e caberia, preliminarmente, discutir, com mais profundidade, o seu conceito de necessidades básicas 11, atacado por terceiros-mundistas radicais como armadilha ideológica, inventada para negar uma reestruturação mais profunda da economia internacional, assim como a tese, ainda recentemente levantada, de graduação do Brasil e de outros países em estágio similar de desenvolvimento. Igualmente, o BID e todos os governos de países atual ou potencialmente credores teriam que ser trabalhados. Para isso, seria necessário intensificar o esforço para repensar algumas de nossas atitudes em relação aos Estados Unidos, para o que a próxima visita presidencial àquele país oferece oportuna ocasião. Não devemos, é claro, submeter-nos a alinhamentos automáticos, nem abrir mão de nossa independência e da defesa intransigente de nossos objetivos nacionais e interesses permanentes. Mas podemos evitar atritos desneces- 
12. A tese parece-se com o slogan do início dos anos sessenta, de "repúdio à dívida externa", sentido pouco construtivo que alguns ainda dão à idéia de "renegociar" a divida. sários, dentro de relacionamento mais maduro e mutuamente proveitoso. Afinal, querer marginalizar o centro desafia, no mínimo, a geometria.

Também o diálogo diplomático sobre o tema teria de adensar-se com os países europeus, o Japão, a Arábia Saudita, enfim, todos os governos que tenham voz e peso no espaço internacional não só diretamente, se não também através dos organismos reguladores já referidos, ou pela influência que possam exercer sobre os agentes privados e nas organizações internacionais. Ao mesmo tempo, deveremos - sem aceitar a tese de um cartel dos devedores, que mais se parece com um pacto mútuo de suicídio financeiro12 - batalhar em outros foros internacionais, como a Conferência para o Comércio e o Desenvolvimento, ou Reuniões de Chefes de Estado ou Governo, como a de Cancun, para pleitear a mudança das regras do jogo, com o apoio, naturalmente, de outros países que vivam problemas paralelos de balanço de pagamento.

É enorme a complexidade envolvida. Não se trata, pois de proposição a curto prazo, mas é importante começar desde já reflexão objetiva e desapaixonada sobre a matéria.

Um ponto que vale ainda referir é o de que, se a pulverização dos atores torna, de um lado, qualquer negociação mais difícil, de outro, pode facilitá-la, caso formos capazes de aproveitar a emulação entre os diversos credores, recorrendo mais a uns do que a outros, conforme a disposição momentânea de cada um. Momentos tem havido em que a Europa, por exemplo, tem sido mais flexível, em termos de financiamento. Em outros, são os banqueiros nos Estados Unidos que são mais agressivos, ou, como no início da década dos 70, o Japão. Há, portanto, possibilidade e conveniência de procurar-se um equilíbrio, análogo ao já conquistado pela diversificação da pauta de exportação, na captação de financiamentos, evitando posições monolíticas, e assegurando um afluxo mais confiável e uma razoável margem de segurança, no caso de eventuais crises ou inflexibilidades localizadas do sistema financeiro internacional.

\section{Conclusões tentativas}

À guisa de resumo, poderíamos pinçar algumas conclusões tentativas, sem pretender à abrangência ou ao dogmatismo:

1) A atual dívida externa é grande, mas não desmesurada e, conseqüentemente, pode ser gerenciada sem maiores sustos ou atropelos, caso encarada com prudência e realismo.

2) A comunidade financeira internacional que nos empresta a prazos relativamente longos (prazo mínimo de 8 anos e médio de 4 a 5 anos para os empréstimos da Resolução n. 63 ou da Lei n. 4.131) gostaria de conhecer com mais nitidez, sem pretender a adivinhaç̃̃es futurológicas, o horizonte temporal da evolução econômica brasileira no prazo de vigência de seus empréstimos.

3) Esse conhecimento pressupõe esforço interno intensificado no sentido de traçar políticas menos sujeitas a flutuações erráticas e 
capazes de assegurar um mínimo de estabilidade nas regras do jogo, ao abrigo de soluções imediatistas.

4) Poder vislumbrar tendências a mais longo prazo coincide com a necessidade do empresariado brasileiro de poder contar com horizontes que informem suas decisões de investimento, e com a aspiração de grande parte da sociedade brasileira. Um programa, amplamente discutido e que transite através de um processo de efetiva coparticipação, proporcionaria autoridade, aceitação espontânea e força de mobilização de esforços interna que reforçariam nossa posição negociadora externa.

5) Quando dispusermos de uma tal estratégia abrangente e consensual, poderíamos procurar negociar, mesmo que informalmente, certa tranqüilidade no acesso às poupanças externas, que o programa traçado considerasse necessárias para complementar as poupanças domésticas, que sempre serão o esteio principal e preponderante de nosso desenvolvimento. Os mais variados agentes financeiros poderiam ser abrangidos nesse esforço de parlamentação, tanto públicos, quanto privados, tanto internacionais, quanto nacionais.

6) Diálogo pressupõe coordenação efetiva entre políticas internas e externas, assim como política exterior mais abrangente que nos sirva de respaldo no processo de negociação financeira, o qual é complexo, difícil e delicado e do qual seria, pois, imprudente esperar resultados imediatos ou milagrosos.

7) É premente, para evitar o perigo de esgarçamento do tecido social, implantar-se, como prioridade da agenda nacional, política interna que enfrente com destemor, pertinácia, racionalidade e compaixão, o que nossos antepassados já chamavam de questão social, procurando assegurar o acesso de enorme parcela de nossa população, ainda marginalizada, aos frutos materiais do progresso, às condições mínimas de sobrevivência digna e à plena dimensão da cidadania moderna: a liberdade responsável e a participação política consciente. Como primeiro passo, há que erradicar-se os bolsões de pobreza absoluta, que constituem chaga dolorosa na consciência nacional. Esforço em tal sentido é precondição para adensar a legitimidade de nossos pleitos nos foros mundiais, em busca de uma Nova Ordem Econômica Internacional, que, sem inibir os mecanismos de mercado, inspire-se em princípios de igualdade, eficácia e justiça. 